removed by biopsy at daily intervals and assayed for lipoprotein lipase activity. The preparation of acetone-ther-dried powders and assay conditions were essentially as described by Robinson (1963), except that the triglyceride substrate was an activated coconut oil and the free fatty acids released on incubation were estimated colorimetrically (Vaughan, Berger \& Steinberg, 1964).

The sequential course of response to prolactin is characterized by a significant increase in activity on the third day rising to a $300-400 \%$ increase on the fourth day. The activity in the absence of exogenous prolactin during this period of pseudopregnancy was low and relatively constant, and the intraductal injection of $0.15 \mathrm{M}-\mathrm{NaCl}$ had no effect on lipoprotein lipase activity.

Intraductal administration of actinomycin D $4 \mathrm{hr}$. before, simultaneously with, or one or two days after prolactin, prevented any increase in activity. In a second series of experiments actinomycin D given on the third day after prolactin caused abolition of the lipase activity. Parallel experiments with cycloheximide gave results similar to those described for actinomycin $\mathrm{D}$.

In experiments to determine the half-life of this prolactin-activated lipoprotein lipase, and of the system responsible for its biosynthesis, actinomycin D was injected on the fifth day after prolactin stimulation. From the rate of decrease of lipase activity over a $10 \mathrm{hr}$. period the approximate halflife of the system was found to be $4 \mathrm{hr}$.

From similar experiments in which cycloheximide was used to inhibit protein synthesis, the half-life of the enzyme appeared to be less than $1 \cdot 5 \mathrm{hr}$.

It was tentatively concluded from these results that activation of lipoprotein lipase in the mammary gland of pseudopregnant rabbits requires RNA biosynthesis and the subsequent biosynthesis of enzyme protein.

Chadwick, A. (1962). Biochem.J. 85, 554.

McBride, O. W. \& Korn, D. (1963). J. Lipid Res. 4, 17.

Robinson, D. S. (1963). J. Lipid Res. 4, 21.

Vaughan, M., Berger, J. E. \& Steinberg, D. (1964). J. biol. Chem. 239, 401.

\section{Isomers of Glucosaminylphosphatidylglycerol}

By P. J. R. Phizackerley and J. C. MacDougall. (Nuffield Department of Clinical Biochemistry, University of Oxford)

Glucosamine derivatives of phosphatidylglycerol have been described in Pseudomonas ovalis Chester (Phizackerley, MacDougall \& Francis, 1966) and in Bacillus megaterium (Op den Kamp, Houtsmuller \& van Deenen, 1965). The phosphoglycolipid from $B$. megaterium has been characterized as $1(-1,2-$ diacyl - sn - glycero - 3 - phosphoryl ) - 2 - $O$ - (2 - amino 2-deoxy-D-glucopyranosyl)-sn-glycerol and this structure has been confirmed by chemical synthesis (Gurr, Bonsen, Op den Kamp \& van Deenen, 1968).

We have examined the lipids of $B$. megaterium and find at least three glucosamine-containing lipids. One of these is not a phospholipid but the other two, which differ in their chromatographic behaviour, contain phosphorus, glycerol, fatty acid and glucosamine in the molar proportions $1: 2: 2: 1$. In both cases fatty acids are liberated by mild alkaline hydrolysis, and both yield phosphatidylglycerol after deamination with nitrite. However, the glucosaminylglycerols derived from these lipids by partial acid hydrolysis in $2.0 \mathrm{~N}-\mathrm{HCl}$ for $8 \mathrm{hr}$. at $105^{\circ}$ differ in their behaviour towards periodate. In one case, 1 mole of periodate/mole of glucosaminylglycerol is rapidly consumed, whereas in the other case, under identical conditions, the consumption of periodate is negligible. This result indicates that in the first case glucosamine is attached to the $3^{\prime}$ position of the glycerol moiety of phosphatidylglycerol, and in the second case the attachment is to the 2'-position. Both lipids have been $N$ acetylated, and after removal of fatty acids by mild alkaline hydrolysis, $N$-acetylglucosamine is quantitatively released by $\beta-N$-acetylhexosaminidase from calf brain (Frohwein \& Gatt, 1967). It is concluded that in both lipids the glycosidic link has the $\beta$ configuration.

The glucosaminylphosphatidylglycerol from Pseudomonas ovalis is a $2^{\prime}$-glucosaminide. The $N$-acetyl derivative of the deacylated lipid is not a substrate for $\beta-N$-acetylhexosaminidase, but instead $N$-acetylglucosamine is released by $\mathbf{a}$ preparation from Patella vulgata that contains $\alpha$ - $N$-acetylhexosaminidase (Conchie \& Levvy, 1957). It seems probable therefore that in this lipid glucosamine is bound as an $\alpha$-glycoside.

All three phosphoglycolipids are good substrates for phospholipase A, and all appear to be resistant to phospholipase $\mathrm{C}$ from Clostridium perfringens, but only the $3^{\prime}$-glucosaminide is rapidly hydrolysed by phospholipase $\mathrm{D}$, yielding phosphatidic acid and glucosaminylglycerol.

Conchie, J. \& Levvy, G. A. (1957). Biochem. J. 65, 389.

Frohwein, Y. Z. \& Gatt, S. (1967). Biochemistry, 6, 2775.

Gurr, M. I., Bonsen, P. P. M., Op den Kamp, J. A. F. \& van Deenen, L. L. M. (1968). Biochem. J. 108, 211.

Op den Kamp, J. A. F., Houtsmuller, U. M. T. \& van Deenen, L. L. M. (1965). Biochim. biophys. Acta, 106, 438.

Phizackerley, P. J. R., MacDougall, J. C. \& Francis, M. J. O. (1966). Biochem. J. 99, $21 \mathrm{c.}$ 